\title{
To the Etiopathogenes Gestosa Pregnant
}

\author{
Shaposhnikov Veniamin Ivanovich* \\ Kuban Medical Institute, Head Chair of morphologic disciplines, Professor of surgical diseases, Russia \\ *Corresponding author: Shaposhnikov Veniamin Ivanovich, Kuban Medical Institute, Head Chair of morphologic \\ disciplines, Professor of surgical diseases, Vice Rector, Russia
}

\section{ARTICLE INFO}

Received: 幽 October 30, 2019

Published: November 06, 2019

Citation: Shaposhnikov Veniamin I. To the Etiopathogenes Gestosa Pregnant. Biomed J Sci \& Tech Res 22(4)-2019. BJSTR. MS.ID.003774.

Keywords: Pregnancy; Hestosis; Embryo; Fetal Urinary System

The Aim of the Study: Reflect the importance of the fetal urinary system in the development of gestosis in the mother.

\section{ABSTRACT}

The author examines the current problem of modern medicine related to toxicosis in pregnancy. The fact is that this pathological process is still a mystery to doctors. Several theories have been proposed, but they cannot explain the cause of toxicosis in the early and late stages of pregnancy. According to WHO statistics, up to 90 per cent of all pregnant women suffer from toxicity in the first trimester of pregnancy and about 40 per cent in the third trimester. The author of the article has formed the opinion that in the development of gestosis (toxicosis in the third trimester) it is important to actively include in the metabolic process of the embryo's urinary system. His urine does not have time to suck from the bladder and on the urethra begins to periodically flow into the uterine cavity of the mother, causing poisoning of her body. This is the reason for the sharp deterioration of her condition. Vomiting urges increase up to 10-25 times a day, and they are not associated with eating. There is a weight loss of up to $10 \mathrm{~kg}$. There is weakness. The heart rate increases and blood pressure decreases. The temperature rises, there is bad breath, and the woman becomes inhibited. Some of them may have impaired kidney function, and an artificial termination of pregnancy is already required. All these symptoms immediately pass after childbirth, which only confirms the fairness of the proposed version of the cause of pathology and dictates the need to develop an adequate and effective treatment for this pathological process.

\section{Introduction}

Why a pregnant woman's physiological process of embryo development is very often complicated by toxicosis, i.e. the pathological process, remains a mystery to modern medicine. There are early and late toxicosis of pregnancy, with early may begin either from the first days after conception of a new life, or at 5-6 weeks of pregnancy, and ends by 13-14 weeks. It is observed in almost all pregnant women $[1,4]$. This complication is explained by the toxic effects of the embryo on the mother's homeostasis, when she has not yet formed the placenta - it is formed only by 12-14 weeks. Late toxicosis (hestosis) usually begins 30 weeks from the beginning of pregnancy - in the last (third) of her trimester, and sometimes even in the middle of the second, and then it proceeds heavier. It is observed in almost half of pregnant women. There are 4 forms of gestosis - water of pregnant women, nephropathy, preeclampsia, eclampsia. When waterside, water lingers in the body with the development of swelling. In nephropathy there is swelling, high blood pressure, protein in the urine. In pre-eclampsia there is a violation of the function of the nervous system. In eclampsia there are convulsions and loss of consciousness. The cause of gestosis has not yet been determined [2-4]. If early toxicosis, with a certain degree of doubt, the authors explained, or neuroreflex reactions from the effects of the embryo on the endometrial of the uterus, or poisoning by toxins coming from fetal tissue, or chorionic gonadotropic hormone, or they could not explain the late toxicosis.

It was not clear why the fetus suddenly began to pose a mortal danger to the mother in the last 2-3 months of life in her body. At this time, she had pronounced symptoms of inflammation in the abdominal cavity - constant abdominal pain, increased body temperature, tachycardia, drop in blood pressure, excruciating multiple vomiting, leukocytosis, increase in fertilized water, rotten breath $[5,6]$. Careful analysis of this clinical picture of the disease suggested that this is not an accidental negative phenomenon, but a certain pathological process associated with the impending birth of a child. At this time, his mother begins to feel his movements, which inevitably should have led to the strengthening of his metabolic processes. This is accompanied by increased kidney and rectal 
function. However, if the opening has a reliable locking mechanism - in the form of internal and external sphincters, the urethra is deprived of it. Not only has that, the preponderability in the inertia of the parasympathetic nervous system, over the sympathetic, made it unstable to stretch. As a result, the fetus does not have time to suck urine from the bladder cavity and begins to flow through the urethra into the uterine cavity. This was accompanied by the development of the inflammatory process. Determining the cause of gestosis allowed to revise the algorithm of treatment.

\section{Material and Methods}

Working as a district homeowner for 16 years, I had to constantly do an examination of patients in the department of pathology of pregnant women. The main reason for their hospitalization was toxicosis. At a young age it was particularly difficult. Attempting to combat swelling only led to increased intoxication, although diuretics were part of the standard algorithm for treating these patients. This discomfort from treatment forced not only to reconsider the tactics of treatment of these pregnant women, but also to take a fresh look at the etiopathogeny of this pathological process. These observations formed the basis of the new theory of gestosis, as was reported above. To combat swelling, instead of diuretic began to limit the intake of fluid, and intoxication was reduced due to the normalization of the stool - making it daily and voluminous. This was achieved by taking bran, vegetables and fruits. Diet therapy was purely individual, but it was forbidden to take salty and irritating food. At the same time prescribed corrective infusion therapy, fat emulsion, vitamins and sedatives.

\section{Result}

The treatment was meaningful. His main task was to bring the pregnancy to delivery. After that, all the suffering of the woman ceased. No fatalities were observed. Completely to rid a patient of

\section{ISSN: 2574-1241}

DOI: 10.26717/BJSTR.2019.22.003774

Shaposhnikov Veniamin Ivanovich. Biomed J Sci \& Tech Res

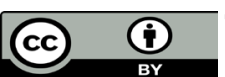

This work is licensed under Creative Commons Attribution 4.0 License

Submission Link: https://biomedres.us/submit-manuscript.php the painful symptom complex was not possible, which testified to the resilience of the pathological process, and the need to correct homeostasis before delivery.

\section{Discussion}

Despite the simplicity of the treatment, it allowed to reduce the phenomenon of gestosis after 2-3 days. This was mainly due to the normalization of the chair - severe intoxication caused by prolonged constipation (3-4 days or more) was eliminated. Restricting the intake of fluids reduced the fruit's urine production. Both of these activities were more of an organizational than a therapeutic one.

\section{Conclusion}

The development of late toxicosis in pregnant women is associated with the flow of urine from the fetal bladder into the uterine cavity of the mother. This occurs during the increased movement of the fetus and is natural. At this time it is necessary to achieve the normalization of the chair in a woman - it should be voluminous and daily. This effectively reduces her intoxication and reduces the water load. As a result, the plov decreases urine production and it is absorbed in his bladder. These activities are more of an organizational nature than a therapeutic one.

\section{References}

1. Bryn VB (2016) Normal Physiology. ( $3^{\text {rd }}$ edn) In Tkachenko BI (Eds.). Geotar Media, Russia, pp. 688s.

2. Degtyarev VP, Sorokina ND (2016) Normal Physiology. Geotar Media, Russia, pp. 480c.

3. Kamkin AG, Kisilova IS (2013) Atlas in Physiology in Two Volumes. Geotar Media, Russia, pp. 408s.

4. Svirskaya ES (2010) Pregnancy from conception to childbirth (1 $1^{\text {st }}$ edn). Peter pp. 272s.

5. Tela LS, Aghajanyan NA (2015) Normal Physiology. Lit Terra pp. 768s.

6. Yuan Y, Ren J, He Y (2013) Current status of the open abdomen treatment for intra-abdominal infection. Gastroenterology Res Pract 2013: 532013.

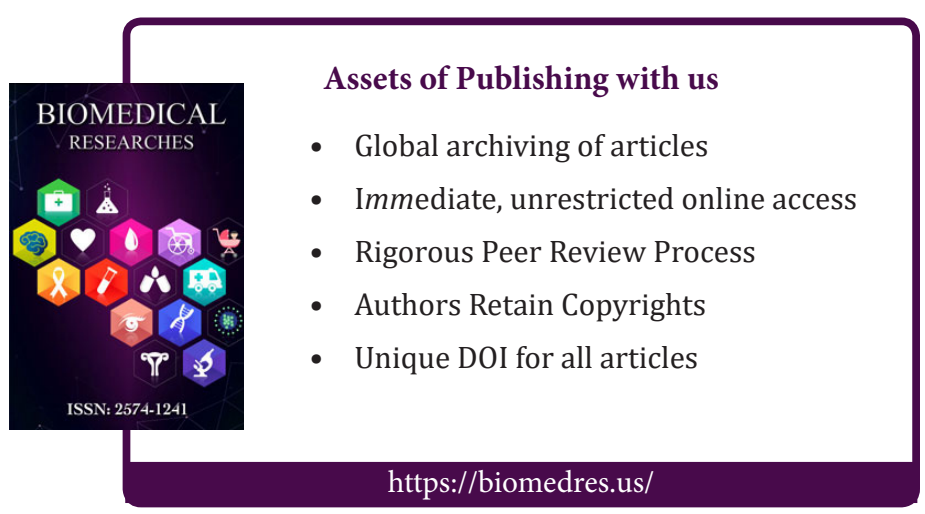

